\title{
Mobile computing tool to help treat autistic children with difficulties in recognizing and interpreting facial expressions
}

\author{
Alves-Ribeiro, Francisco Adelton \\ Education Department, \\ Federal Institute of Education, Science and \\ Technology of Maranhão - Brazil \\ adelton@ifma.edu.br \\ Schalcher-Pereira, Álvaro Itaúna \\ Education Department, \\ Federal Institute of Education, Science and \\ Technology of Maranhão - Brazil \\ alvaro.pereira@ifma.edu.br \\ Ribeiro, Vanessa de Oliveira \\ Education Department, \\ Compuservis Informática - Brazil \\ adv.vanessaribeiro@gmail.com
}

Souza-Carneiro, Pedro Lucas Education Department, Federal Institute of Education, Science and

Technology of Maranhão - Brazil pedro.lucas.root@gmail.com

Carvalho, Gabriel Borges Education Department, Federal Institute of Education, Science and

Technology of Maranhão - Brazil carvalhobrgs@gmail.com

Vieira-Paula, Danilo Bruno Education Department, Federal Institute of Education, Science and

Technology of Maranhão - Brazil d.brunno18@gmail.com

\section{Abstract:}

This work presents a game titled Face: a game to aid treatment of autistic children through the interpretation and recognition of facial expressions, developed by the team multidisplinar of the Federal Institute of Education, Science and Technology of Maranhão (IFMA), using the methodology of Applied Behavior Analysis (ABA), commonly associated with the treatment of children with Disorders of the Autism Spectrum disorders (ASD). The application divide the learning of facial expression in small tasks, containing positive reinforcement each time the child wins or loses. The educator has access to the settings menu of the game, can increase or reduce the amount of interaction between the child and the game can select the facial expression to be worked. The first screen of the game displays an image chosen by the educator, presented a screen with " $n$ " bins "m", in order to improve the learning of the facial expression desired. After the child be able to reach all the " $n$ " screen positions, more interaction will be added with the goal of strengthening the 
Mobile computing tool to help treat autistic children with difficulties in recognizing ...... Alves-Ribeiro Schalcher-Pereira Ribeiro Souza-Carneiro Carvalho Vieira-Paula

learning. In each phase, a new image, in different positions, it will be displayed on the screen, representing different levels in the game, this process is repeated during all phases of the game. In the end, the educators have access to the report containing the results corresponding to each phase of the game, with the amount of interaction, amount ringtones on other buttons, the amount of touches on other buttons, amount ringtones on out of buttons, time spent to complete each phase, as well as their statistics.

Keywords - Autism; Education; Game; Psychology.

\section{INTRODUCTION}

Autism Apectrum Disorder (ASD), in general, can be defined by persistent impairments in interaction and social communication, with difficulty in expressing and understanding other people's feelings, in addition to the presence of repetitive and restricted patterns of behavior. Such characteristics may vary according to the severity and nature of the symptoms. The ASD has no known etiology and understands, more specifically, autism or autistic disorder $[1,5,8]$.

The authors $[2,3,6,9]$, indicate that "[...] autism and the autism spectrum disorders (ASD) have the strongest evidence they have genetic bases", they emphasize that the data are reliable and that the recent findings in the area offer the possibility of advances in the discovery of the real cause of autism and other spectrum disorders $[4,7]$.

In the present work, we present a game-oriented to aid in the teachinglearning process of autistic children with difficulties in the recognition and interpretation of facial expressions. 


\section{THE GAME:}

The Face-ABA presents itself as a game with the purpose to assist professionals from Education and Psychology in the teaching of interpretation and recognition of facial expressions for children with autism spectrum, the Fig. 01 the initial screen of the game and the Fig. 02 shows the configuration menu of the game.

Fig. 1 - InitialscreenFace-ABA

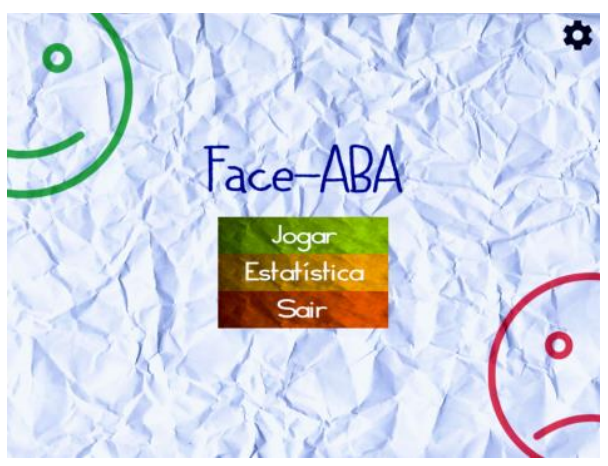

Source: Authors, 2018
Fig. 2 - Configurationmenu of thegame

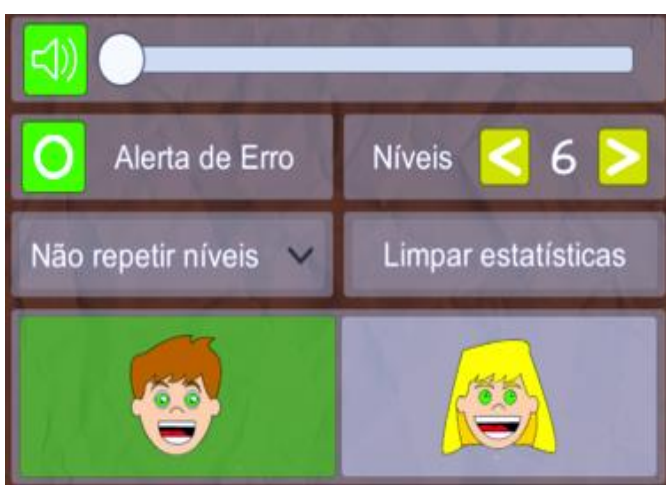

Source: Authors, 2018

Given the amount of interaction " $\mathrm{m}$ " so as to reinforce the learning of the facial expression desired. After the child be able to reach all the " $n$ " screen positions, more interaction will be added with the goal of strengthening the learning. In each phase, a new image, in different positions, it will be displayed on the screen, representing different levels in the game, this process is repeated during all phases of the game, as shown in Fig. 3.

Fig. 3 - Phases of the game

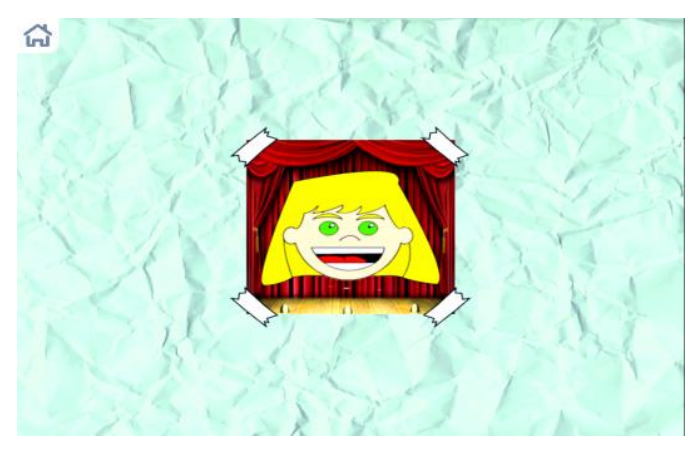

Source: Authors, 2018 
Mobile computing tool to help treat autistic children with difficulties in recognizing ......

Alves-Ribeiro Schalcher-Pereira Ribeiro Souza-Carneiro Carvalho Vieira-Paula

\section{GAMEPLAY:}

When entering the first phase of the game, with only one picture, the player starts his interaction with the game setting the expression facial to be worked. By clicking on the character will be automatically directed to the second stage, if the player click on the wrong in the image nothing happens, and when you click the correct one will be taken to the next stage of the game, the following stages follow the same dynamic, in this way the third phase is composed of three images with only a proper interaction, and so on, passing by the fourth and fifth phase, ending with the sixth phase consisting of six images, as shown in Fig. 4.

Fig. 4 - Phases of the game

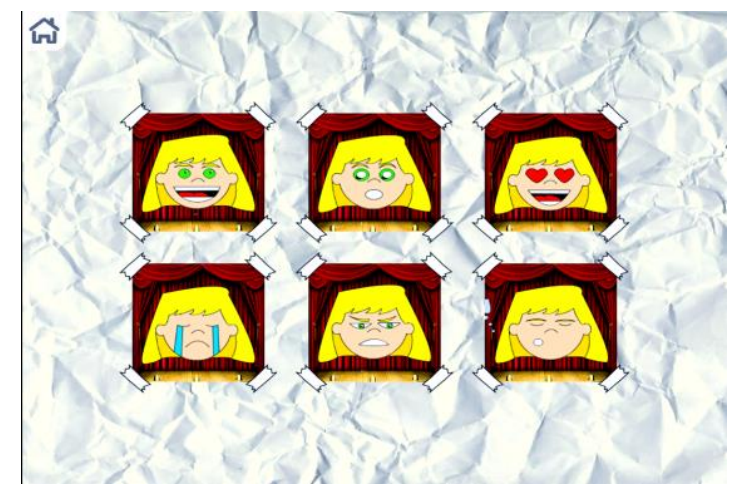

Source: Authors, 2018

At the end of your first experience with the game the player is taken to a new screen containing all the positive reinforcement and containing statistics of the game, as shown in Fig. 5.

Fig. 5 - The End of the first experience with Game Face-ABA

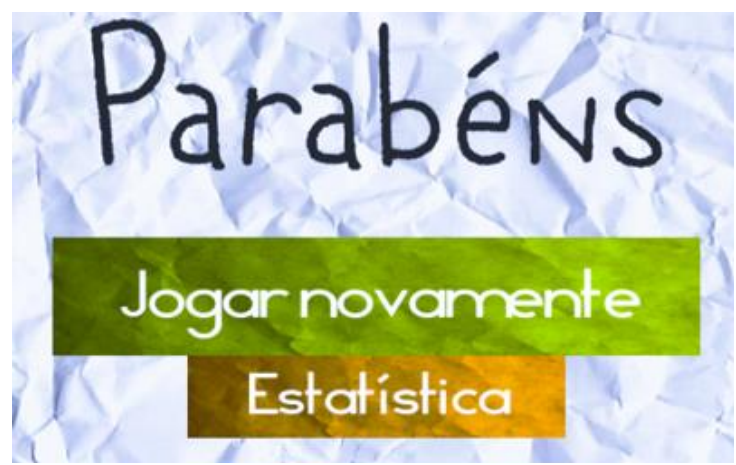

Source: Authors, 2018 


\section{Referências}

[1] A. S. G. Correia, "A competência no reconhecimento da expressão facial da emoção: Estudo empírico com crianças e jovens com Perturbação do Espetro do Autismo," Porto: UFP, 2014.

[2] F. Belisário and J. F.cunha, "A educação especial na perspectiva da inclusão escolar: transtornos globais do desenvolvimento," Brasília: Ministério da Educação, Secretaria de Educação Especial, 2010.

[3] M. G. Aman, and S. A. Armstrong, "Regarding secretin for treating autistic disorder" [Letter to the editor ]. Journal of Autism and Developmental Disorders, 30, 71-72, 2000.

[4] W. A. Banks, M. Goulet, J. R. Rusche, M. L Nieho and R. Boismenu, "Differential transport of a secretin ana-log across the blood-brain and bloodcerebrospinal. uid barriers of the mouse". The Journal of Pharmacology and Experimental Therapeutics, 302, 1062-1069, 2002

[5] A. R. Gupta, and M. W. State, "Autismo: genética, Revista Brasileira de Psiquiatria,” São Paulo, v. 28, supl. I, p. 29-38, fev. 14, 2018.

[6] M. G. Chez and C. P. Buchanan, "Reply to B. Rimland's "comments on 'secret in and autism:A two-part clinical investigation", "Journal of Autism and Developmental Disor-ders, 30, 97, 2000

[7] M. G. Chez, C. P. Buchanan, B. T. Bagan, M. S. Hammer, K. S. McCarthy and I. Ovrutskaya, "Secretin and autism:A two-part clinical investigation". Journal of Autism and Developmental Disorders, 30, 87-94,2000.

[8] K. Horvath, J. C. Papadimitriou, A. Rabsztyn, C. Drachenberg and J. T. Tildon, "Gastrointestinal abnormalities in chil-dren with autistic disorder". Journal of Pediatrics, 135, 559-563, 1999.

J. S. Schwartzman, "Transtornos do espectro do autismo: conceitos e generalidades," São Paulo: Memnon, p. 37- 42, 2011. 